\title{
Effects of cigarette smoking on sensorineural hearing impairment and age related macular degeneration
}

\author{
Marina Istrate', Mihai Hasbei-Popa², Daniela A. Iliescu ${ }^{3,4}$, Ana C. Ghita ${ }^{3}$, Aurelian M. Ghita ${ }^{3,4}$
}

\begin{abstract}
INTRODUCTION Cigarette smoking has been causally associated with various diseases, and among the numerous harmful effects of smoking is included its impact on the senses of vision and hearing. The purpose of this study is to evaluate the impact of cigarette smoking on the visual and auditory functions.

METHODS In this analytic study, hearing and smoking status of 40 patients with agerelated macular degeneration (AMD) were analyzed with 40 age-matched control subjects without AMD. In all subjects $(n=80)$, retinal status was investigated by optical coherence tomography (OCT), with analyses of thickness central subfield (TCS) and thickness average cube (TAC) of the macula. All participants were examined with pure tone audiometry. Audiometric trials comprised pure tone bone and air conduction. The smoking history of all the subjects was recorded in detail.

RESULTS A significant correlation was found between smoking status and visual $(\mathrm{p}<0.001)$ and hearing impairment $(\mathrm{p}<0.05)$. Cigarette smoking was found to be highly correlated with sensorineural hearing impairment and exudative macular degeneration.

CONCLUSIONS Cigarette smoking damage anti-oxidative systems and tissue metabolism. We have underlined a clear correlation between the risk of sensorineural hearing impairment, exudative macular degeneration and cigarette smoking. Our findings may result in future screening of smokers to identify any hearing and vision impairment and for improving smoking cessation interventions.
\end{abstract}

\begin{abstract}
AFFILIATION
1 Faculty of Medicine, Victor Babes University of Medicine and Pharmacy, Timisoara, Romania 2 Faculty of Medicine, Iuliu Hatieganu University of Medicine and Pharmacy, Cluj-Napoca,

Romania

3 Ocularcare Eye Clinic, Bucharest, Romania

4 Department of Physiology,

Faculty of Medicine and Pharmacy, Carol Davila University of Medicine and Pharmacy, Bucharest, Romania
\end{abstract}

\section{CORRESPONDENCE TO}

Marina Istrate. Faculty of Medicine, Victor Babes University of Medicine and Pharmacy, 2 Eftimie Murgu Square, 300041, Timisoara,

Romania. E-mail: istratemarina@ yahoo.com

\section{KEYWORDS}

smoking, oxidative damage, microvascular abnormalities, hearing impairment, loss of vision

Received: 29 November 2020 Revised: 13 February 2021

Accepted: 14 June 2021

\section{INTRODUCTION}

Cigarette smoke is an intricate mixture of chemical substances that are attached to aerosols or are free in gaseous phase. Current research suggests that cigarette smoke includes more than 4000 chemical compounds ${ }^{1,2}$. Numerous classes of chemicals present in cigarette smoke are triggers for various diseases ${ }^{1-3}$.

The tobacco leaves are rich in alkaloids, but nicotine is the most abundant. Therefore, the alkaloid content includes: nicotine $\mathrm{N}^{\prime}$-oxide, myosmine, $\beta$-nicotyrine, cotinine, 2,3'-bipyridyl, anabasine, nornicotine, $N$-methylanabasine, anatabine, anabaseine and nicotine $\mathrm{e}^{2,3}$.

Nicotine has numerous harmful effects and is well known to be very addictive. Nicotine is a dibasic substance and its absorption is related to the $\mathrm{pH}$ of the solution ${ }^{2}$. There are three forms of nicotine and all have great solubility in water and dissolve easily in blood $^{2}$.

Therefore, nicotine has the ability to increase the quantity of free radicals and reactive oxygen species that trigger oxidative damage and cause tissue suffering. Also, nicotine stimulates the nuclear factor kappa B (NF-kB), which is implicated in 
inflammatory processes and cell damage ${ }^{2}$. Cigarette smoking damages nearly every organ of the body and induces the marked detrimental effects on the endothelial cells of the blood vessels. It causes increased endothelial cell proliferation and intimal hyperplasia. The vasoconstricting effects of smoking damage the oxygenation of the adjacent tissues ${ }^{4,5}$. Some of these negative effects are immediate while others are slower. Cigarette smoking causes oxidative stress with harmful effects on humans. Age-related macular degeneration (AMD) is a gradual degenerative impairment of the retina associated with damage of central vision ${ }^{6}$. The retinal pigment epithelium (RPE) contains a large quantity of melanin. RPE melanin plays a photoprotective role by absorbing radiation and contributing to the elimination of free radicals ${ }^{7,8}$. Melanin suffering and microvascular insufficiency are important causes in the pathogenic processes of $\mathrm{AMD}^{9-11}$. The cochlea is a structure of the inner ear which has in componence the organ of Corti and stria vascularis. Melanocytes are abundant in the inner ear and stria vascularis includes most of the melanin ${ }^{12,13}$. Melanin defends the structures of the inner ear against oxidative damage ${ }^{14-16}$. One side effect of cigarette smoking is decreased oxygen supply to the cochlea. This may result in constant hardship of the cochlea and moderate to severe hearing damage ${ }^{17}$. Also, cigarette smoking increases the risk of developing macular degeneration ${ }^{18}$. The correlation between simultaneous retinal and cochlear impairment may be due to melanin dysfunction and microvascular damage ${ }^{19}$. Melanin deficiency might initiate the apoptosis of retinal pigment epithelial cells and cochlear elements which are abundant in melanin. Oxidative stress caused by cigarette smoking triggers microvascular abnormalities and melanin deficiency, therefore smoking is highly associated with risks of hearing and visual loss ${ }^{16,20-22}$.

\section{METHODS}

In our analytic study, hearing and smoking status of 40 patients with AMD were compared with 40 agematched control subjects without AMD. All subjects were referred to the Ocularcare Eye Clinic during a 12-month period from March 2019 to March 2020. The study protocol was approved by the ethics committee of 'Victor Babes' University of Medicine and Pharmacy, Timisoara, Romania. All procedures performed in this study involving human participants were in accordance with the ethical standards of the institutional and national research committee and with the Helsinki Declaration and its later amendments or comparable ethical standards. Informed consent was obtained from all individual participants included in the study.

The study population was represented by patients aged $65-75$ years. In all individuals, retinal changes were validated by fundoscopy and optical coherence tomography (OCT), by analysis of thickness central subfield (TCS) and thickness average cube (TAC) of the macula. Cases and controls were excluded if they had other infectious inflammatory or retinovascular disorders, such as diabetic retinopathy, hypertensive retinopathy, retinal vascular occlusion or retinochoroiditis that could confuse the diagnosis of degenerative maculopathy. Based on Wisconsin age-related maculopathy grading system (WARMGS), the term AMD is attributed to geographic atrophy (GA), retinal drusen, choroidal neovascularization (CNV) and pigment epithelial detachment (PED) ${ }^{9}$. Patients were enrolled as cases if they had AMD in one or both eyes. Subjects without AMD were accepted in the control group.

\section{Audiometry}

All patients were inspected with pure tone audiometry. Audiometric trials comprised pure tone audiometry at frequencies ranging from 125-8000 $\mathrm{Hz}$. Pure tones were used to analyze air and bone conduction. Audiometry was performed by using an AMPLIVOX LTD series 240 Portable Audiometer by an experienced audiologist. The cases of congenital hearing loss and the subjects who did not collaborate on audiometric trials were excluded from the study. The audiometric investigation was done to establish the type and the degree of the hearing impairment. The severity of the hearing loss was classified as normal $(\leq 20 \mathrm{~dB})$, mild $(>25 \mathrm{~dB}$ and $\leq 40 \mathrm{~dB})$, moderate $(>40 \mathrm{~dB}$ and $\leq 60 \mathrm{~dB})$, and severe $(>60 \mathrm{~dB})$, based on the pure tone average. The allotment into normal hearing, conductive, mixed and sensorineural hearing loss was done in conformity with the audiometric results. 


\section{Smoking history}

Smoking data were assembled in the same way for both cases and controls. Smoking status was assessed as non-smoker and current smoker. The smoking group included patients that had a history of more than 10 cigarettes/day. Patients from the non-smoking group had no history of smoking. The questionnaire comprised the number of cigarettes smoked per day in each decade of life, exposure to passive smoking and use of other tobacco products. To acquire pack-years of smoking, the number of years of smoking was multiplied by the number of packs of cigarettes smoked per day ${ }^{2}$.

\section{Statistical analysis}

The statistical analysis was performed by using SPSS,

Table 1. Age, sex and smoking data for cases and controls

\begin{tabular}{|c|c|c|}
\hline Characteristics & $\begin{array}{c}\text { Cases }(n=40) \\
\text { Exudative } \\
\text { AMD }(n=31) \\
\text { Atrophic } \\
\text { AMD }(n=9) \\
n(\%)\end{array}$ & $\begin{array}{c}\text { Controls } \\
(n=40)\end{array}$ \\
\hline Age (years), mean $\pm S D$ & $67.2 \pm 5.5$ & $68.4 \pm 4.2$ \\
\hline \multicolumn{3}{|l|}{ Sex } \\
\hline Male & $23(57.5)$ & $21(52.5)$ \\
\hline Female & $17(42.5)$ & $19(47.5)$ \\
\hline \multicolumn{3}{|l|}{ Smoking status } \\
\hline Non-smoker & $6(15.0)$ & $37(92.5)$ \\
\hline Smoker & $34(85.0)$ & $3(7.5)$ \\
\hline \multicolumn{3}{|l|}{$\begin{array}{l}\text { Categorical pack-years of } \\
\text { cigarette smoking }\end{array}$} \\
\hline 0 & $6(15.0)$ & 37 (92.5) \\
\hline $1-10$ & $5(12.5)$ & $2(5.0)$ \\
\hline $10-30$ & $2(5.0)$ & - \\
\hline$>30$ & $27(67.5)$ & $1(2.5)$ \\
\hline \multicolumn{3}{|c|}{$\begin{array}{l}\text { Passive smoking exposure (non- } \\
\text { smokers) }\end{array}$} \\
\hline No & $1(16.7)$ & $23(62.2)$ \\
\hline Yes & $5(83.3)$ & $14(37.8)$ \\
\hline \multicolumn{3}{|c|}{$\begin{array}{l}\text { Categorical pack-years of } \\
\text { smoking other tobacco products }\end{array}$} \\
\hline 0 & $6(15.0)$ & 37 (92.5) \\
\hline $1-10$ & $25(62.5)$ & $2(5.0)$ \\
\hline $10-30$ & $9(22.5)$ & $1(2.5)$ \\
\hline$>30$ & - & - \\
\hline
\end{tabular}

version 22.0. Data assayed using logistic regression models for categorical variables are presented in relation to a reference category. The variables such as smoking status, type of hearing and vision damage, thickness central subfield and thickness average cube of the macula were reported as numeric variables. The results are summarized as odds ratios with $95 \%$ confidence interval (CI), with significance set at an alpha level of $5 \%(\mathrm{p} \leq 0.05)$.

\section{RESULTS}

The study included 40 patients with AMD and 40 age-matched control subjects without AMD. Summary data and smoking history are presented in Table 1. The mean age of cases was $67.2(\mathrm{SD}=5.5)$ years and of controls was $68.4(\mathrm{SD}=4.2)$ years. On analyzing the audiometric results, it was noticed that cigarette smoking was found to be statistically associated with hearing impairment $(\mathrm{p}<0.05)$ (Table 2 ), especially sensorineural hearing impairment (HN), thus $75.68 \%$ of smokers were identified with sensorineural hearing loss (Figure 1). No statistically significant difference was found among other types of hearing loss. Regarding the correlation between age related macular degenaration (AMD) and smoking status, we noticed that $70.27 \%$ of smokers had exudative macular degeneration (AMDe) and $21.62 \%$ had atrophic macular degeneration (AMDa) (Figure 2$)$, respectively $(\mathrm{p}<0.001)$ (Table 2$)$. No significant consequence of cigarette smoking on thickness average cube (TAC) was detected (Figure 4). However, smoking affected the foveal thickness (TCS) (Figure 3).

Table 2. Hearing and visual health conditions according to smoking status

$\begin{array}{lccc}\text { Characteristics } & \text { Mean } & \%(95 \% \text { CI }) & p \\ \begin{array}{l}\text { Visual impairment } \\ \text { Atrophic AMD }\end{array} & 1.11 & 1.11(0.892-1.33) & <0.001 \\ \begin{array}{l}\text { Exudative AMD } \\ \text { No visual impairment }\end{array} & 1.16 & 1.16(1.03-1.29) & \\ \text { Hearing impairment } & & 1.93(1.85-2.01) & \\ \text { Sensorineural hearing loss } & 1.10 & 1.1(0.994-1.21) & \\ \text { Conductive hearing loss } & 1.67 & 1.67(1.26-2.08) & \\ \text { Mixed hearing loss } & 1.63 & 1.63(1.27-1.99) & \\ \text { No hearing impairment } & 1.89 & 1.89(1.78-2.00) & \end{array}$


Figure 1. The effect of smoking on hearing status (N-normal hearing, HN-sensorineural hearing loss, HTconductive hearing loss, HM-mixed hearing loss)

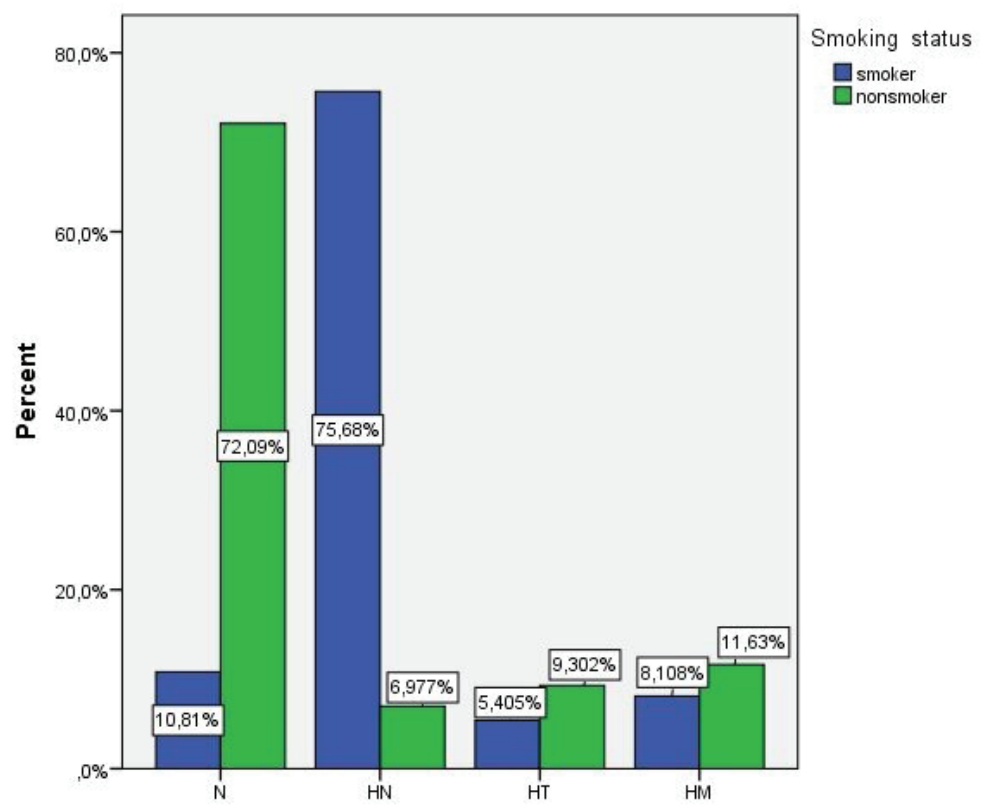

Figure 2. Relationship of cigarette smoking and visual impairment (AMDa-atrophic macular degeneration, AMDe-exudative macular degeneration)

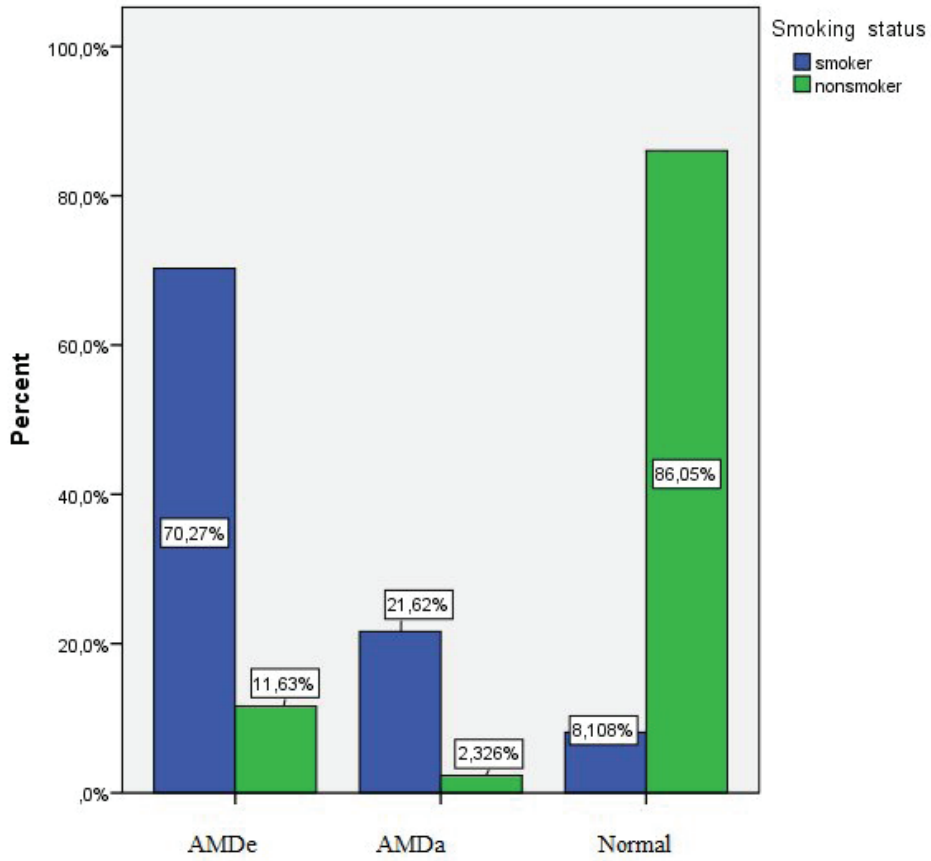


Figure 3. The boxplot analysis of thickness central subfield of the macula among smokers and non-smokers

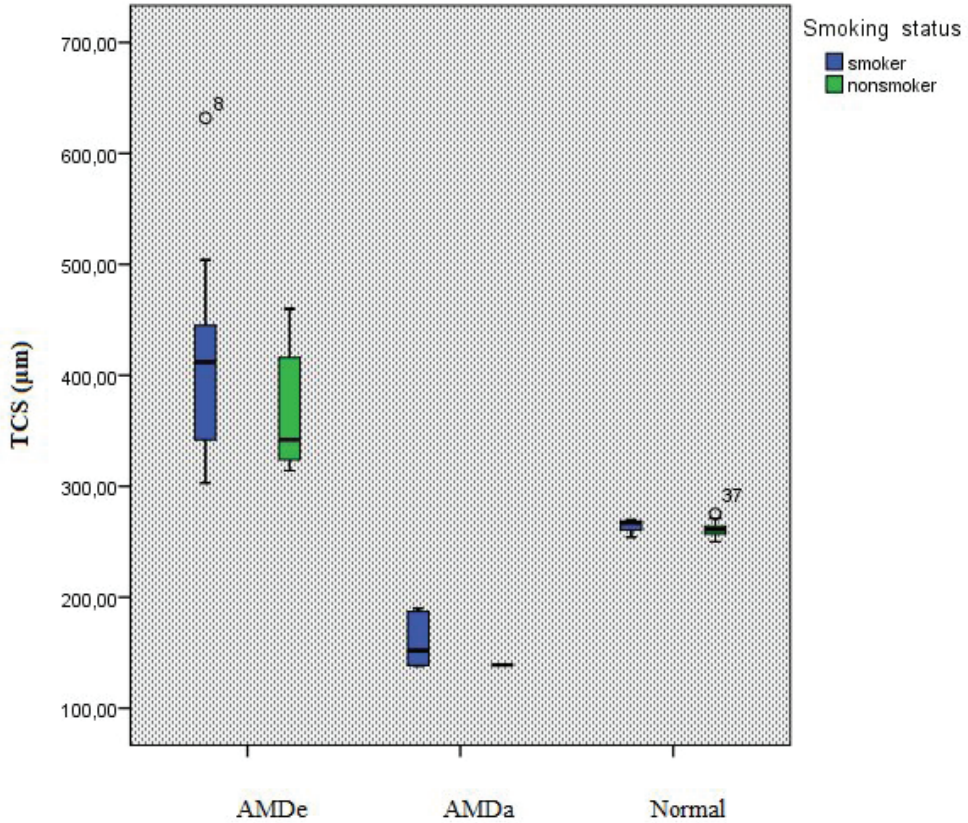

Box plots of median percentages for smokers (blue color) and non-smokers (green color) across thickness central subfield of the macula (TCS) based on visual health status. The median percentage is indicated by the line that splits the box into two portions. Data outside the whiskers are outliers. The lower and upper whiskers denote scores outside the middle $50 \%$

Figure 4. The boxplot analysis of thickness average cube of the macula among smokers and non-smokers

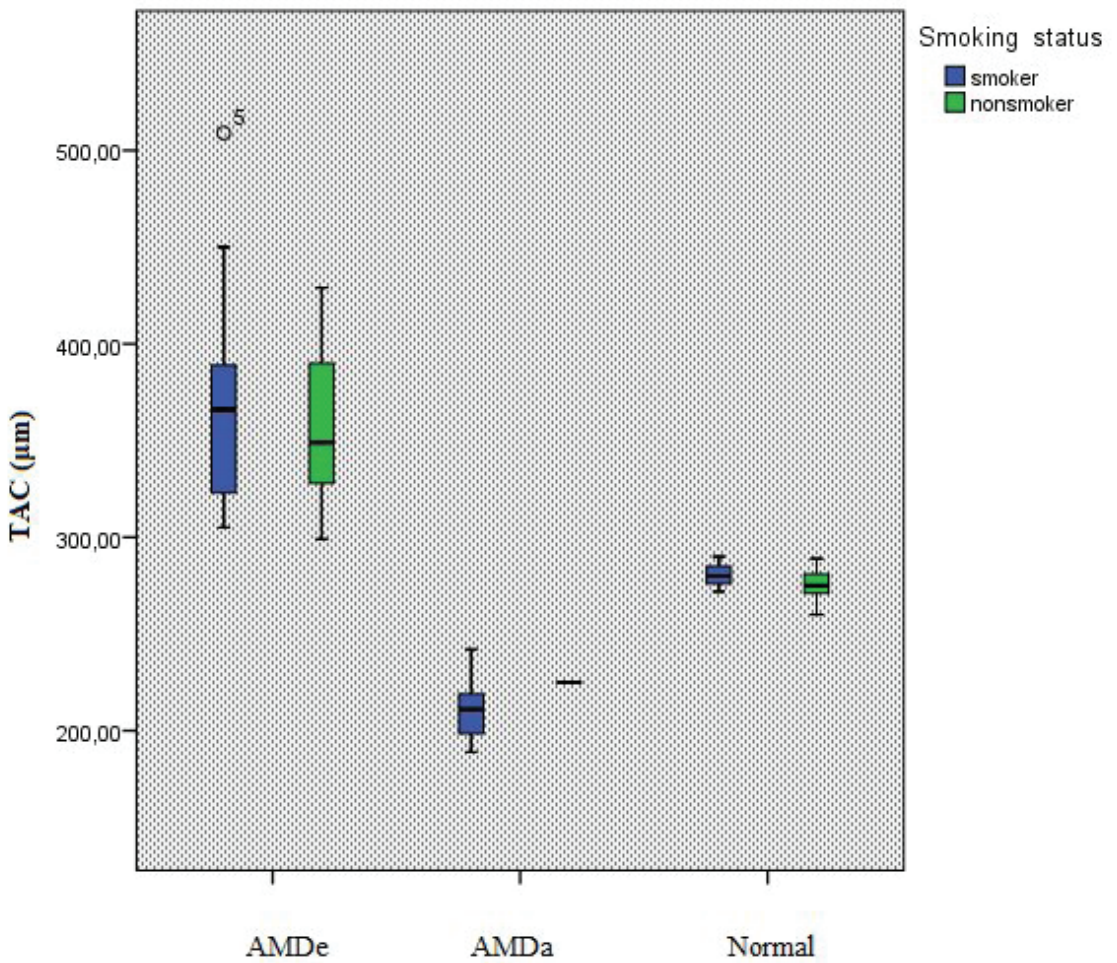

Box plots of median percentages for smokers (blue color) and non-smokers (green color) across thickness average cube of the macula (TAC) based on visual health status. The median percentage is indicated by the line that splits the box into two portions. Data outside the whiskers are outliers. The lower and upper whiskers denote scores outside the middle $50 \%$. 


\section{DISCUSSION}

In the current study, cigarette smoking was found to be statistically correlated with sensorineural hearing impairment. Sensorineural hearing impairment (HN) is caused by distress of the cochlear sensory epithelium or the peripheral auditory neurons. The sensory component is due to damage of organ of Corti or to an insufficiency of hair cells to stimulate the auditory nerve. The neural element refers to when damage is proximal to the cochlea and auditory nerve (retrocochlear damage $)^{23-25}$. Conductive hearing loss (HT) is characterized by obstruction or illness in the outer or middle ear. Consequently, a mixed hearing loss (HM) implies a combination of conductive and sensorineural hearing damage, respectively the problem occurs in the outer or middle and the inner $\mathrm{ear}^{25,26}$.

Several distinctions were noticed in terms of smoking status between AMD patients and control group. Conventionally, AMD has been classified into two main categories: exudative (AMDe) and nonexudative or atrophic (AMDa). AMD is a common cause of irreversible central vision loss. Patients with AMD in one eye have about a 50\% probability of developing AMD in the contralateral eye ${ }^{27-30}$. The complete diagnosis is based on fundoscopy and optical coherence tomography (OCT) which can differentiate exudative and atrophic types of macular degeneration. Optical coherence tomography (OCT) allows us to analyze in vivo the retinal layers. Macular thickness parameters such as thickness central subfield (TCS) and thickness average cube (TAC) are very important for analyzing retinal changes and to distinguish normal macular features from atrophic or exudative changes ${ }^{30}$.

The present study revealed that cigarette smoking shows a significant association with visual and hearing impairment. Consistent with our study findings, other studies have reported a highly significant association between current smoking and sensorineural hearing loss and age-related macular degeneration ${ }^{4,17,18,28}$. Cigarette smoking has pernicious effects on the retinal tissues and inner ear. This provides powerful support for a causal relation between cigarette smoking and the prevalence of sensorineural hearing loss and agerelated macular degeneration.

Two phases have been recognized in cigarette smoke, gas and tar phases, which are abundant in free radicals and non-radical oxidants. Particularly, hydroxyl radical and peroxyl are implied in oxidative stress and tissue malady. We emphasized the hint of possible similar roles of melanin in progress of these two disorders in the retinal tissues and inner ear. Stria vascularis in the Corti structure of the cochlea is the basic structure including melanocytes. The number of Corti structures and melanocytes is lower at the base of the cochlea. Small melanin concentration makes the cochlear base more responsive to oxidative stress and lipofuscin aggregation. One way through which the chemicals found in cigarette smoke may produce an effect on hearing status, is by provoking injury to the antioxidative systems and to the ear vasculature ${ }^{2,28}$. On the other hand, melanin in the RPE cells defends photoreceptors against oxidative stress ${ }^{29}$. Melanin dysfunction as the most important fact in AMD, determines low to severe visual loss and blindness. In fact, RPE cells and photoreceptors act as a functional unit for the visual system ${ }^{30}$. Therefore, melanin alteration caused by oxidative stress might account for important concomitant visual and hearing impairment ${ }^{31-33}$. Cigarette smoke is known to be rich in chemical compounds ${ }^{5}$. The two most toxic constituents of cigarette smoke are nicotine and carbon monoxide, however, cigarette smoke contains about 4000 additional toxic components. Cigarette smoking decreases the blood supply due to the vasospasms induced, favors the atherosclerotic narrowing of the blood vessels and accelerates ischemic damage due to increased blood viscosity and by thrombotic occlusions with endothelial changes of the vessels ${ }^{34,35}$. One of the means through which the chemicals found in cigarette smoke may have an effect on cochlea is by causing vasculopathy. Besides this, chemicals found in cigarette smoke damage cochlear melanin. Also, the oxidative stress and microvascular damages provoke deficiencies in the metabolic bed of RPE with apoptosis of photoreceptor cells. Cigarette smoke implies a great number of prooxidant compounds $\mathrm{s}^{4,36}$ and also consists of dioxins, which are moderated by aryl hydrocarbon receptor (AhR), which is a liganddependent transcriptional factor widely expressed among immune, epithelial, endothelial and stromal cells in barrier tissues. Dioxin affects ocular tissues 
through the AhR pathway, develops vascular endothelial growth factor (VEGF) production in human RPE cells which potentiates retinal exudation by neovascularization ${ }^{37-39}$.

\section{Strengths and limitations}

Due to a group of subjects who did not collaborate on audiometric trials, we had to exclude them from the study. Despite these limitations, important information were obtained. Baseline data regarding the nocive influence of cigarette smoking on the retina and the inner ear can be used to establish future cessation and prevention strategies.

\section{CONCLUSIONS}

We outlined the hypothesis of possible similar roles of melanin and microvascular abnormalities in development of retinal degeneration and hearing impairment. We also would like to emphasize the role of cigarette smoking on these disturbances. It seems to have two mechanisms. One is provoking injury to the anti-oxidative systems, the other is inducing vasculopathy and damage to tissue metabolism.

\section{REFERENCES}

1. Hoffmann D, Hoffmann I. The changing cigarette, 19501995. J Toxicol Environ Health. 1997;50(4):307-364. doi:10.1080/009841097160393

2. U. S. Department of Health and Human Services. How Tobacco Smoke Causes Disease: The Biology and Behavioral Basis for Smoking-Attributable Disease: A Report of the Surgeon General. U.S. Department of Health and Human Services; 2010:30-77. Accessed February 13, 2021. https://www.ncbi.nlm.nih.gov/ books/NBK53017/pdf/Bookshelf_NBK53017.pdf

3. Hoffmann D, Hoffmann I. Letters to the editor, tobacco smoke components. Beitr Tab Int. 1998;18(1):49-52. doi:10.2478/cttr-2013-0668

4. Cong R, Zhou B, Sun Q, Gu H, Tang N, Wang B. Smoking and the risk of age-related macular degeneration: a meta-analysis. Ann Epidemiol. 2008;18(8):647-656. doi:10.1016/j.annepidem.2008.04.002

5. Heeschen C, Jang JJ, Weis M, et al. Nicotine stimulates angiogenesis and promotes tumor growth and atherosclerosis. Nat Med. 2001;7(7):833-839. doi:10.1038/89961

6. Age-Related Eye Disease Study Research Group. Risk factors for the incidence of Advanced Age-Related Macular Degeneration in the Age-Related Eye Disease Study (AREDS) AREDS report no. 19. Ophthalmology. 2005;112(4):533-539. doi:10.1016/j.ophtha.2004.10.047
7. Niculescu CT, Carmaciu R, Voiculescu B, Nita C, Salavastru C, Ciornei C. Anatomia si Fiziologia Omului: Compendiu. Human anatomy and physiology: Compendium. Editura Corint; 2014:222-226.

8. American Academy of Ophthalmology. Fundamentals and Principles of Ophthalmology. American Academy of Ophthalmology; 2011:303-308. Basic and Clinical Science Course, Section 2. Accessed February 13, 2021. https:// gr1lib.org/dl/1161326/e18892

9. Dumitrache M. Tratat de oftalmologie. Vol 2. Universitara Carol Davila; 2012:1094-1122.

10. Holz FG, Pauleikhoff D, Klein R, Bird AC. Pathogenesis of lesions in late age-related macular disease. Am J Ophthalmol. 2004;137(3):504-510. doi:10.1016/j. ajo.2003.11.026

11. Zarbin MA. Current concepts in the pathogenesis of age-related macular degeneration. Arch Ophthalmol. 2004;122(4):598-614. doi:10.1001/archopht.122.4.598

12. Tachibana M. Cochlear Melanocytes and MITF Signaling. J Investig Dermatol Symp Proc. 2001;6(1):95-98. doi:10.1046/j.0022-202x.2001.00017.x

13. Masuda M, Yamazaki K, Kanzaki J, Hosoda Y. Ultrastructure of melanocytes in the dark cell area of human vestibular organs: functional implications of gap junctions, isolated cilia, and annulate lamellae. Anat Rec. 1994;240(4):481-491. doi:10.1002/ar.1092400406

14. Dumont P, Burton M, Chen QM, et al. Induction of replicative senescence biomarkers by sublethal oxidative stresses in normal human fibroblast. Free Radic Biol Med. 2000;28(3):361-373. doi:10.1016/s08915849(99)00249-x

15. Stone EM, Aldave AJ, Drack AV, et al. Recommendations for Genetic Testing of Inherited Eye Diseases: Report of the American Academy of Ophthalmology Task Force on Genetic Testing. Ophthalmology. 2012;119(11):24082410. doi:10.1016/j.ophtha.2012.05.047

16. Murillo-Cuesta S, Contreras J, Zurita E, et al. Melanin precursors prevent premature age-related and noiseinduced hearing loss in albino mice. Pigment Cell Melanoma Res. 2010;23(1):72-83. doi:10.1111/j.1755148X.2009.00646.x

17. Zelman S. Correlation of smoking history with hearing loss. JAMA. 1973;223(8):920. doi:10.1001/jama.1973.03220080050016

18. Ni Dhubhghaill SS, Cahill MT, Campbell M, Cassidy L, Humphries MM, Humphries P. The pathophysiology of cigarette smoking and age-related macular degeneration. Adv Exp Med Biol. 2010;664:437-446. doi:10.1007/978-1-4419-1399-9_50

19. Schneck ME, Lott LA, Haegerstrom-Portnoy G, Brabyn JA. Association between hearing and vision impairments in older adults. Ophthalmic Physiol Opt. 2012;32(1):4552. doi:10.1111/j.1475-1313.2011.00876.x

20. Schmidt SY, Peisch RD. Melanin Concentration in Normal Human Retinal Pigment Epithelium. 
Regional Variation and Age-Related Reduction. Invest Ophthalmol Vis Sci. 1986;27(7):1063-1067. Accessed February 13, 2021. https://iovs.arvojournals.org/article. aspx?articleid=2177531

21. Bozkurt MK, Ozturk BT, Kerimoglu H, Ersan I, Arbag H, Bozkurt B. Association of age-related macular degeneration with age-related hearing loss. J Laryngol Otol. 2011;125(3):231-235. doi:10.1017/ S0022215110002604

22. Charls WC, Jhon MF, Lee AH, Chars JK, Mark AR, David ES. Cochlear anatomy and central auditory pathways. In: Santi PA, Mancini P, eds. Otolaryngology-Head \& Neck Surgery. 3rd ed. Elsevier; 1998:1-25.

23. Blitzer A, Schwartz J, Song P, Young N. Oxford American Handbook of Otolaryngology. Oxford University Press; 2008:276-281.

24. Lee KJ. Essential Otolaryngology: Head and Neck surgery. 11th ed. McGraw-Hill Education; 2015:218-355.

25. Legent F, Perlemuter L, Vandenbrouck C. Cahiers d'Anatomie O.R.L. Atlas of ENT. Masson; 1968.

26. Guyton AC, Hall JE. Textbook of Medical Physiology. 11th ed. Saunders; 2005:626-660. Accessed February 13, 2021. https://www.moscmm.org/pdf/Guyton\%20 physiology.pdf

27. Fazelat A, Bahrani H, Buzney S, Lashkari K, Weiter JJ. Autoimmunity and age-related macular degeneration: a review of the literature. Semin Ophthalmol. 2011;26(45):304-311. doi:10.3109/08820538.2011.588666

28. Nomura K, Nakao M, Morimoto T. Effect of smoking on hearing loss: quality assessment and meta-analysis. Prev Med. 2005;40(2):138-144. doi:10.1016/j. ypmed.2004.05.011

29. Coleman AL, Seitzman RL, Cummings SR, et al. The Association of Smoking and Alcohol Use With Agerelated Macular Degeneration in the Oldest Old: The Study of Osteoporotic Fractures. Am J Ophthalmol. 2010;149(1):160-169. doi:10.1016/j.ajo.2009.07.025

30. Yanoff M, Duker J. Ophthalmology. 4th ed. Saunders; 2013:580-626.

31. Weiter JJ, Delori FC, Wing GL, Fitch KA. Relationship of senile macular degeneration to ocular pigmentation. Am J Ophthalmol. 1985;99(2):185-187. doi:10.1016/0002-9394(85)90230-2

32. Chia EM, Mitchell P, Rochtchina E, Foran S, Golding M, Wang JJ. Association between vision and hearing impairments and their combined effects on quality of life. Arch Ophthalmol. 2006;124(10):1465-1470. doi:10.1001/archopht.124.10.1465

33. Liew G, Wong TY, Mitchell P, Newall P, Smith W, Wang JJ. Retinal microvascular abnormalities and age-related hearing loss: the Blue Mountains hearing study. Ear Hear. 2007;28(3):394-401. doi:10.1097/ AUD.0b013e3180479388

34. Heeschen C, Chang E, Aicher A, Cooke JP. Endothelial Progenitor Cells Participatein Nicotine-Mediated
Angiogenesis. J Am Coll Cardiol. 2006;48(12):25532560. doi:10.1016/j.jacc.2006.07.066

35. Yu M, Liu Q, Sun J, Yi K, Wu L, Tan X. Nicotine improves the functional activity of late endothelial progenitor cells via nicotinic acetylcholine receptors. Biochem Cell Biol. 2011;89(4):405-410. doi:10.1139/o11-032

36. Fowles J, Dybing E. Application of toxicological risk assessment principles to the chemical constituents of cigarette smoke. Tob Control. 2003;12(4):424-430. doi:10.1136/tc.12.4.424

37. Campochiaro PA. Retinal and choroidal neovascularization. J Cell Physiol. 2000;184(3):301-310. doi:10.1002/10974652(200009)184:3<301::AID-JCP3>3.0.CO;2-H

38. Hoffman EC, Reyes H, Chu FF, et al. Cloning of a factor required for activity of the $\mathrm{Ah}$ (dioxin) receptor. Science. 1991;252(5008):954-958. doi:10.1126/science.1852076

39. Reyes H, Reisz-Porszasz S, Hankinson O. Identification of the Ah receptor nuclear translocator protein (Arnt) as a component of the DNA binding form of the Ah receptor. Science. 1992;256(5060):1193-1195. doi:10.1126/science.256.5060.1193

\section{ACKNOWLEDGEMENTS}

The authors are grateful to the Ocularcare Eye Clinic for the encouragement and support for this work.

\section{CONFLICTS OF INTEREST}

The authors have completed and submitted the ICMJE Form for Disclosure of Potential Conflicts of Interest and none was reported.

\section{FUNDING}

There was no source of funding for this research.

\section{ETHICAL APPROVAL AND INFORMED CONSENT}

This study was approved by the ethics committee of Victor Babes University of Medicine and Pharmacy, Timisoara, Romania (No. 05/2019). All procedures involving human participants were performed in accordance with the ethical standards of the institutional and national research committee, and the WMA Declaration of Helsinki. Informed consent was obtained from all participants in the study.

\section{DATA AVAILABILITY}

The data supporting this research cannot be made available for privacy or other reasons.

\section{PROVENANCE AND PEER REVIEW}

Not commissioned; externally peer reviewed. 